\title{
Entrevista com François Dubet Estigmas e discriminações - a experiência individual como objeto ${ }^{1}$
}

\author{
Interview with François Dubet \\ Stigma and discrimination - the individual experience as object \\ Entrevista con François Dubet \\ Estigmas y discriminaciones - la experiencia individual como objeto \\ ÉDER DA SILVA SILVEIRA*
}

François Dubet é sociólogo, professor, coordenador e orientador de pesquisas na Université Bordeaux II e na École des Hautes Études en Sciences Sociales (EHESS) de Paris, França. Pesquisador do Centre d'Analyse et d'Intervention Sociologiques (CADIS/ EHESS), desenvolveu relevantes pesquisas no campo da sociologia. Dubet é autor e organizador de diversos trabalhos, sendo que, dentre eles, destacam-se estudos sobre questões relativas à Educação, movimentos sociais e, recentemente, sobre estigmas e discriminações. A partir de suas pesquisas, cunhou a noção teórica de "Sociologia da Experiência", tema que resultou no livro Sociologie de l'expérience (1994), publicado também no Brasil posteriormente. Dentre outros trabalhos de destaque do pesquisador, estão: La galère: jeunes en survie (1987), obra na qual Dubet realiza uma análise da experiência e das condutas de jovens de periferias da França e, ao mesmo tempo, do sistema social e suas mudanças a partir da crise de um modelo de sociedade industrial; Les Lycéens (1991), A l'école: sociologie de l'expérience scolaire (1996), L'hipocrisie scolaire (2000), e L'école des chances: q'est-ce qu'une école juste? (2004), foram algumas produções que evidenciaram a temática da experiência escolar; em Le travail des sociétés (2009), apresenta uma reflexão teórica na qual retoma e aprofunda algumas questões apresentadas em Sociologie de l'expérience (1994), destacando as noções de sociedade, coesão e integração social, experiência e dominação.

A entrevista com François Dubet foi realizada em Paris, em $1^{\circ}$ de fevereiro de 2013, no CADIS/EHESS. O tema abordado foi o mesmo do Seminário ministrado por Dubet entre 2012/2 e 2013/1 (Sociologie de l'experiénce

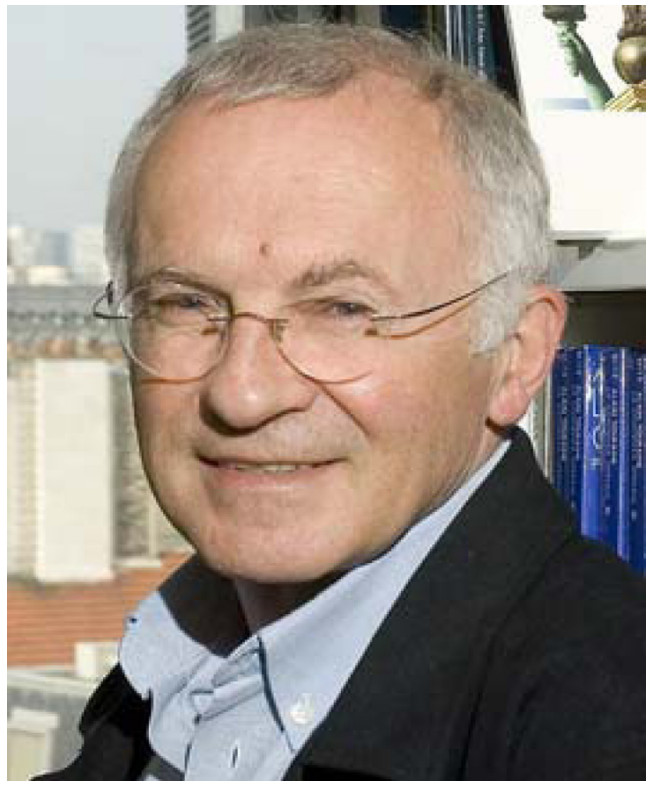

PROFESSOR FRANÇOIS DUBET

Fonte: Centre D'analyseet D'intervencion Sociologiques.**

sociale - Stigmates et discriminations), no qual participei como aluno durante o estágio de Doutorado (bolsa PDSE/CAPES) realizado na mesma universidade. Duas semanas após a entrevista, Dubet lançou o livro tema de seu seminário: Pourquoi moi? L'expérience des discriminations. (Paris: Éditions du Seuil, 2013), ainda sem tradução no Brasil. A seguir, compartilho com os leitores o resultado da entrevista, gentilmente concedida pelo pesquisador francês, a quem agradeço mais uma vez pela atenção e generosidade.

\footnotetext{
* Doutor em História pela Universidade do Vale do Rio dos Sinos (São Leopoldo, RS, Brasil) e professor na Universidade de Santa Cruz do Sul (Santa Cruz ** do Sul, RS, Brasil).E-mail: <eders@unisc.br>.

** Disponível em: <http://cadis.ehess.fr/index.php?/membres-du-centre/membres-associes/1137-francois-dubet>. Acesso em: 18 mar. 2015.
} 
- Éder: Professor, o senhor poderia iniciar falando-nos um pouco sobre sua formação e trajetória profissional?

$\square$ François Dubet: Minha primeira formação foi em engenharia. Após cursei filosofia, porém, não conclui, pois me senti "fechado" (no sentido que o curso parecia essencialmente teórico). Então, por acaso, eu descobri a sociologia. Digo por acaso, pois quando fiz meus estudos a sociologia não tinha muito espaço na Academia como disciplina. No fundo eu encontrei na sociologia a possibilidade de satisfazer o prazer da especulação filosófica, mas também o gosto pela realidade, comum aos engenheiros.

Fiquei verdadeiramente seduzido pela sociologia. Naquela época, não havia inquietude sobre o emprego. O final dos anos 60 , por exemplo, foi um período pleno de emprego e, por isso, podíamos fazer nossos estudos e teríamos trabalho a qualquer momento.

Lembro-me de não ter sido um excelente estudante, mas tinha um grande espírito de liberdade. Trabalhei paralelamente aos meus estudos, e isso foi muito agradável. Minha verdadeira formação ocorreu aqui (EHESS), quando encontrei Alain Touraine. Eu já tinha aproximadamente 30 anos e ensinava na universidade quando Alain Touraine propôs que nos lançássemos em uma aventura extraordinária, que foi a "Sociologia dos Novos Movimentos Sociais", a partir de um método também extraordinário que foi a "intervenção sociológica". Então, durante seis ou sete anos, eu poderia dizer que aprendi verdadeiramente a sociologia, não a sociologia acadêmica, mas a essência da sociologia. Exatamente naquele momento ocorriam as lutas estudantis, as lutas ecológicas, as lutas regionais; saímos a campo, fomos à Polônia, etc. Alain Touraine foi verdadeiramente um mestre e um companheiro. Ele tinha uma reputação formidável. Trabalhamos muito juntos. Para mim foi uma chance extraordinária.

Em meados dos anos 1980 mudei completamente de objeto. Passei seis ou sete anos estudando movimentos sociais e, após, interessei-me por problemas relacionados às condutas marginais e juvenis. Tive a sorte de fazer uma pesquisa que obteve certo sucesso e que se chamou La galère. Eu disse que foi uma sorte porque, através dessa pesquisa e de certo sucesso intelectual e midiático que ela teve, adquiri em seguida certa autonomia. Quando fiz 40 anos estava mais ou menos tranquilo. Depois, troquei de objeto novamente.

Minha carreira é caracterizada pela mudança de objetos. Interessei-me, logo após, pela educação. Fiz pesquisas sobre educação, de certa forma com uma abordagem original, pois me interessei em analisar as experiências dos alunos. Então, no início dos anos
90, interessei-me pela educação, alguns aspectos políticos correlatos, enfim, sobre problemas relativos à educação.

Depois, entre os anos 2000 e 2010, também mudei de objeto. Dediquei-me ao problema da justiça social, pesquisei sobre desigualdades, injustiça, sobre o sentimento de justiça, sobre a discriminação. E, como todo mundo, durante essas mudanças de objetos, tentei, de maneira modesta, obter uma linha teórica que descrevi principalmente em dois livros, Sociologie de l'expérience (1994) e dez anos mais tarde, Le travail des sociétés (2009).

Em minha carreira, beneficiei-me de um contexto incrivelmente favorável. Eu encontro Touraine, me torno um sociólogo, meu trabalho teve um pouco de sucesso, pude mudar de objetos - que é uma autonomia formidável.

- Éder: O senhor pensa em retornar a algum dos objetos já pesquisados, como a escola, por exemplo? François Dubet: Hoje começo a entrar em uma idade onde o horizonte começa a raccoucir. Quando você já tem certa idade, pesquisar a escola ou mudar muito de objeto começa a se tornar muito cansativo. Agora a questão que me interessa, atualmente, talvez seja me deslocar da justiça em direção ao que, em um sentido republicano, chamaríamos de fraternidade. O que faz com que as sociedades exclamem o sentimento de solidariedade? O que faz com que os indivíduos se sintam parte de uma mesma sociedade? Evidentemente, essas interrogações estão um pouco ligadas ao contexto histórico e político atual, onde a violência das mudanças sociais passa por uma espécie de vertigem.

- Éder: Atualmente, o senhor continua trabalhando na Universidade de Bordeaux?

$\square$ François Dubet: Sim, na Universidade de Bordeaux e na EHESS, em Paris. A França é um país no qual é necessário ter um vínculo em Paris, pois a concentração da vida política e intelectual está extraordinariamente concentrada nessa cidade.

- Éder: O que o motivou a pesquisar sobre estigmas e discriminações nas experiências individuais?

François Dubet: Eu havia constatado há três ou quatro anos que nós passamos de um regime de representação das desigualdades sociais, muito ancorado na questão da "classe social", em direção a um regime onde se veem as desigualdades a partir da questão da "discriminação". No fundo, na sociedade industrial e clássica, as grandes formas de desigualdade geralmente estão vinculadas ou se formam na questão do trabalho e não se veem 
praticamente os outros. E hoje temos o sentimento de que as grandes desigualdades estão nas maiorias e minorias, nos homens e nas mulheres, etc. A discriminação torna-se uma grande figura das desigualdades.

Diante dessa constatação, a reflexão sociológica que faço é de desconfiar imediatamente de interpretações e modelos ideológicos ou políticos que dizem: "A França é uma sociedade colonial"; "as pessoas estão inseridas numa cultura ou em um modelo de dominação", etc., que geralmente vêm, aliás, da Teoria Crítica francesa revisitada pelas universidades americanas.

Isso, no fundo, é o que dizem os intelectuais e os militantes. Eu prefiro ouvir o que dizem as pessoas que estão envolvidas diretamente no problema. Então não vou perguntar se a França é um país pós-colonial, quero ver as pessoas que são vítimas potencialmente disso. Não vou questionar se as mulheres são sistematicamente discriminadas, vou procurar essas mulheres e perguntar: como isso ocorre para você?

Minha posição sociológica é sempre a mesma, isto é, falo das experiências dos atores sociais. Por exemplo, quando pesquisei a escola, desenvolvi meu trabalho privilegiando as entrevistas com os alunos. Não perguntava se a escola era um aparelho ideológico etc. Perguntava aos alunos como eles vivem a experiência da escola. Trata-se de uma antiga reação de sociólogos dos anos 1950 e 1960. $\mathrm{Na}$ França havia um forte partido comunista e fortes CGTs - organizações sindicais - que falavam em nome dos operários. Diziam o que os trabalhadores pensavam, o que eles acreditavam, sentiam, etc. E o que diziam aos sociólogos? "Não vá perguntar aos operários, porque somos nós que pensamos e respondemos por eles". O trabalho do sociólogo era de ir e ouvir essas organizações. Evidentemente, o que pensavam os operários não era exatamente o que dizia o sindicato ou o partido comunista. Logo, creio que é sempre necessário tentar restituir as experiências dos indivíduos. Tentar se aproximar o mais possível.

- Éder: Como o senhor diferencia "estigmatização" de "discriminação"?

François Dubet: A discriminação é um mecanismo objetivo que faz você dizer ou constatar que se fecham oportunidades, como as de empregos a negros, mulheres, imigrantes, etc. A estigmatização é um conjunto de atitudes depreciativas, estigmatizantes, pejorativas, que diz: "as mulheres são seres inconstantes", "os imigrantes são pessoas desonestas". Então, a estigmatização é um julgamento negativo. A discriminação é um mecanismo objetivo.
É claro que, em geral, a gente pensa que quando se é estigmatizado se é discriminado. Mas uma pessoa pode ser discriminada sem ser estigmatizada. E, algumas vezes, de maneira paradoxal, pode-se ser estigmatizada sem ser discriminada. Por que isto é importante? Porque, se você tem um pouco de distância entre a discriminação e a estigmatização, você tem um espaço de experiência social na qual o ator pode agir. É necessário mostrar que o mundo social não é homogêneo. Eu proponho exatamente esta ideia. Por exemplo, as pessoas de origem magrebina são estigmatizadas e discriminadas: primeira proposição. Segunda proposição: isso depende. Depende do onde, do momento, por quem. Então também é preciso dar conta de todos estes "dependes". Por isso não existe adequação absoluta entre as atitudes culturais e os mecanismos sociais. Por exemplo, se você discrimina, eu diria, espontaneamente, é porque você prefere escolher as pessoas que você conhece. Neste caso, dou preferência a pessoas como eu porque, de alguma forma, a vida é mais fácil com pessoas que são parecidas comigo. E isso não quer dizer que você tenha um julgamento negativo contra os outros. "Eu fiz simplesmente o mais fácil". Aliás, o grupo discriminado fará a mesma coisa entre si. Um chinês preferirá se unir em um bairro chinês para trabalhar com chineses... É mais fácil, e isso não significa que haja hostilidade.

Em outros casos você tem uma hostilidade violenta. Penso que um brasileiro compreende muito bem o que falo, tendo em vista a ambivalência desse tema no Brasil, onde há uma formidável divisão e pluralidade étnico-racial e, ao mesmo tempo, uma relação interpessoal suficientemente boa entre os indivíduos de raças diferentes, porém sem apagar uma divisão estrutural. A partir do que li sobre o Brasil, surpreendeu-me o fato de que "em tal lugar há brancos" e que "em tal lugar há negros", mas quando se encontram individualmente as relações são fraternais, ao contrário de outras sociedades. Então, de certa maneira, você tem forte discriminação e quase nenhuma estigmatização.

- Éder: Tanto a discriminação como a estigmatização estão relacionadas à injustiça social?

François Dubet: Evidentemente. Você tem injustiças sociais em geral, desigualdades sociais em geral, nas quais se misturam mecanismos de discriminação. Então, não se deve confundir discriminação e desigualdade social. Um operário pobre não é discriminado como homem, mas enquanto operário ele é bastante desigual. Uma mulher empresária rica, como empresária ela é respeitada, mas como mulher 
pode ser discriminada. Deve-se aceitar o fato de que um mecanismo jamais exclui o outro.

- Éder: Em sua opinião, na perspectiva da sociologia da experiência, a biografia passa a ter uma relevância maior para os sociólogos?

François Dubet: Nós estamos em uma sociedade culturalmente cada vez mais individualista... Individualista no sentido de que nessa sociedade o indivíduo reivindica sua própria referência. "Eu escolho, por mim mesmo, o que é melhor para mim"... "Eu reivindico o direito de escolher por mim mesmo o que é bom para mim". Por outro lado, nós estamos em uma sociedade extremamente móvel. Isto é, uma sociedade que se transforma de maneira constante... Uma sociedade na qual os indivíduos se deslocam no espaço social. Creio que, em um mundo como esse, o indivíduo torna-se uma unidade da análise sociológica, pois é ele quem vai cristalizar a maior parte dos mecanismos sociais. No fundo, é o indivíduo que, ao se produzir, produz também a vida social. [...] Claro que, nesse sentido, não falo nada de original [...]. Em minha opinião, isso traz um problema às ciências sociais: a força de "ser individualista" talvez possa levar a sociologia a analisar mal a sociedade. O risco é que, se a sociologia não pensa a sociedade, não haverá uma teoria social, e isso seria muito problemático. Mesmo estando em um mundo móvel, individualista, instável, etc., isso não impede que vivamos nessa sociedade. Por isso, minha tendência atual, especialmente a partir de 1994, quando publiquei a Sociologia da experiência, e de 2008-2009, quando escrevi o livro Le travail des societés. Creio que é necessário partir dos indivíduos para compreender a sociedade, e não partir do indivíduo para compreender o indivíduo.

- Éder: O senhor se surpreende com o fato do tema "estigmas e discriminações" se relacionar com interesses tão heterogêneos no campo da pesquisa acadêmica?

$\square$ François Dubet: Sim. Através de muitos trabalhos e teses que oriento, percebo e creio que o tema da estigmatização e da discriminação interessa a muita gente de diversas maneiras.

- Éder: Existe a possibilidade de uma abordagem interdisciplinar...

$\square$ François Dubet: Sim e especialmente aqui na EHESS. Isso, de certa forma, me deixa feliz, principalmente por perceber que essas reflexões são úteis ou passam a ser úteis. [...] O diferencial da EHESS é, por exemplo, os seminários que realizamos.
- Éder: O que mais lhe surpreendeu nessa última pesquisa? ${ }^{2}$

$\square$ François Dubet: Primeiro, o fato que realmente as pessoas reagem como indivíduos, quer dizer, resiste-se mais à discriminação em nome de sua individualidade do que em nome de uma identidade coletiva. Foi uma coisa que me tocou muito, de certa forma, "les gens sont modernes". Segunda coisa que me impressionou, e que falei no seminário, foi o caráter extremamente perverso do mecanismo discriminatório. É perverso, por um lado, paras as vítimas da discriminação e, de certa forma, pelos autores da discriminação. Trata-se de uma questão que me assusta neste mecanismo e que praticamente não conhecemos. Quando você quer lutar contra a discriminação, de certa maneira você produz atitudes que farão com que a discriminação se desloque e a pessoa que se discrimina muda de posição - e isso não é a luta de classes $d u$ diable et le bon dieu. A discriminação é bem mais sutil e complicada que isso.

Uma terceira questão que me surpreendeu é a que ponto, politicamente, torna-se perigoso manipular isso. Nós fizemos essa pesquisa durante o mandato de Nicolas Sarkozy, isto é, em meio a um discurso que de forma crescente estigmatizou os imigrantes, os estrangeiros, os muçulmanos, etc. E nós vemos os efeitos desastrosos desta lógica, pois de certa forma ela não reflete as experiências dos indivíduos. É um mecanismo político que se impõe aos indivíduos. Para dizer de outra forma, no nível de relações individuais isso se passa um pouco diferente. [...] Quando você tem um mise-en-scène político como esse, você tem um efeito desastroso sobre os indivíduos. Os indivíduos dizem: "eu não entendo o que está acontecendo comigo"; "eu não tenho problema e descubro que eu sou um problema para os outros". Nós temos isso hoje no debate sobre a homossexualidade. Um homossexual diz "eu quero ser como os outros, invisível". E me dou conta de que sou um problema para os outros. De certa forma o que reivindico é o direito de não ser um problema. [...]". Penso que existem, no contexto da pesquisa, atores políticos que manipulam esse sentimento abertamente, "une mauvaise action".

- Éder: Uma manipulação retórica, no caso da estigmatização?

François Dubet: Sim, uma manipulação retórica, evidentemente. A estigmatização está nos domínios do imaginário e da retórica, sobretudo do simbólico. Se você diz "os muçulmanos são terroristas", todos os "muçulmanos são terroristas". É uma informação simbólica que muda a vida de franceses muçulmanos que vão tentar um emprego, por exemplo. Pessoas 
que jamais foram terroristas em sua vida e que não têm nenhum sentimento favorável ao terrorismo, mas que ficam com uma marca em sua identidade que pesa negativamente sobre suas imagens e passam a ser vistas como potencialmente perigosas.

- Éder: Podemos relacionar a estigmatização, neste caso, ao conceito de violência simbólica de Pierre Bourdieu?

ㅁ François Dubet: Sim. É uma violência simbólica. Mas, talvez, nem toda estigmatização se encaixe no sentido dado por Bourdieu.

- Éder: Acompanhando seu seminário é possível perceber que haveria instituições que tendem mais à produção de estigmatizações do que outras... $\mathrm{O}$ senhor poderia comentar essa questão e citar alguns exemplos?

François Dubet: Há duas coisas. Existem instituições que de certa forma funcionam um pouco com a estigmatização, por exemplo, a polícia. Para a polícia é uma questão complicada, porque, por um lado podese perceber uma "ideologia racista"; por outro lado, ela está imbricada em uma forma de racionalidade profissional. Se eu procuro um traficante de drogas é melhor que eu investigue e solicite documentos a jovens de origem estrangeira que vivem nos bairros relacionados ao tráfico do que a pessoas brancas entre 60 e 70 anos [...]. As chances de encontrar traficantes de drogas são muito pequenas neste último caso. Então, você tem, objetivamente, como funciona a discriminação. [...] Evidentemente, as pessoas que são vítimas e se sentem discriminadas, muitas vezes, são de "boa-fé".

Então, há instituições nas quais sua lógica de funcionamento produz mais sentimentos de discriminação, ou mais fortes, que outras. Comparamos a escola e o hospital. Partindo da questão, na França, porque na escola as pessoas se sentem discriminadas e em um hospital não se sentem? É muito estranho. Partindo de numerosos casos de preconceitos racistas, não há razão de que isso seja mais forte na escola do que no hospital. Eu diria que não há nenhuma razão para que os professores sejam racistas e os médicos sejam "ruins". De certa maneira, a forma como o hospital acolhe o paciente faz com que a singularidade identitária seja fortemente individualizada, dissolvendo-se em um caso. É um caso: ele é um muçulmano, tem câncer, etc., enquanto a escola é uma instituição que produz desigualdades coletivas, isto é, uma classe de pessoas, de grupos ou estabelecimentos. Há uma adequação de desigualdades sociais e de desigualdades étnicas - até agora vemos estabelecimentos de ensino para estrangeiros, imigrantes, negros, etc.

Indivíduos se dizem objetivamente discriminados, mesmo que nenhuma pessoa os tenha discriminado. Eles vão interpretar todos os incidentes da vida escolar como sinais de discriminação. Imaginemos um exemplo. Em uma sala de aula um professor diz a um grupo de alunos: "Eu não sei mais o que vou fazer com vocês". Na França se diz: "vocês trabalham tão mal que eu não sei o que vou fazer com vocês". Se você diz isso em uma sala na qual há alunos brancos, alunos negros, meninos, meninas, eles entendem exatamente o "eu não sei o que vou fazer com vocês". E quando você diz isso em uma classe de alunos negros, ou somente meninas negras, esta frase torna-se uma frase racista, isto é, "Eu não sei mais o que vou fazer com vocês, negros!". Ou "eu não sei mais o que vou fazer com vocês, meninas negras!". E, então, os alunos dizem: "ele é racista". É do ponto de vista dos alunos que se explica o que aconteceu. Por isso eu falava anteriormente na perversidade desse mecanismo de discriminação e estigmatização: no fundo, tudo pode ser interpretado. Quando você é discriminado, tudo que é dito pode virar contra você. E quando você está do outro lado, tudo que é dito também poderá retornar contra você. Diria que a solução seria, provavelmente, ter consciência disso e transformar o mecanismo institucional. Lutar contra esse mecanismo.

Agradecimentos.

\section{Notas}

1 Entrevista foi realizada originalmente em francês. A tradução é de responsabilidade do entrevistador. Trabalho realizado com auxílio da CAPES, bolsa PDSE.

2 Trata-se de pesquisa sobre experiências sociais com estigmas e discriminações na França contemporânea, particularmente durante o governo de Nicolas Sarkozy. A investigação resultou em seminários ministrados por François Dubet na EHESS: L'expérience de la discrimination (20112012) e Stigmates et discriminations (2012-2013), e na publicação do livro Pourquoi moi? L'expérience des discriminations (2013).

Entrevista recebida em junho 2014

Aprovada em dezembro 2014. 